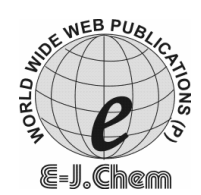

http://www.e-journals.net
ISSN: 0973-4945; CODEN ECJHAO

E-Journal of Chemistry 2008, 5(S2), 1098-1102

\title{
Estimation of Levetiracetam in Tablet Dosage Form by RP-HPLC
}

\author{
N.APPALA RAJU, J. VENKATESWARA RAO*, \\ K.VANITHA PRAKASH, K. MUKKANTI ${ }^{\mathbb{I I}}$ and K. SRINIVASU ${ }^{\#}$ \\ Department of Pharmaceutical Chemistry, \\ Sultan-Ul-Uloom College of Pharmacy, \\ Mount Pleasant, Road No. 3, \\ Banjara Hills, Hyderabad-500 034. \\ ${ }^{\mathrm{II}}$ Centre For Environment, IST Building, \\ Jawaharlal Nehru Technological University, \\ Kukatpally, Hyderabad -500072, India \\ \# Dr.Reddy’s Laboratories, Analytical R\&D, Hyderabad, India. \\ jangalarao@yahoo.com
}

Received 11 February 2008; Accepted 10 April 2008

\begin{abstract}
A simple, precise, rapid and accurate reverse phase HPLC method developed for the estimation of levetiracetam in tablet dosage form. A Sun Fire $\mathrm{C} 18,250 \times 4.6 \mathrm{~mm}, 5 \mu \mathrm{m}$ partical size, with mobile phase consisting of acetonitrile and $0.03 \mathrm{M}$ potassium dihydrogen phosphate $(\mathrm{pH}$ adjusted to 3.0 with orthophosphoric acid) in the ratio of 15:85 v/v was used. The flow rate was $1 \mathrm{~mL}$ $/ \mathrm{min}$ and the effluents were monitored at $210 \mathrm{~nm}$. The retention time was $5.53 \mathrm{~min}$. The detector response was linear in the concentration of $20-240 \mu \mathrm{g} / \mathrm{mL}$. The respective linear regression equation being $\mathrm{Y}=22119.684 \times 6829.3428$. The limit of detection and limit of quantification was 0.16 and $0.5 \mu \mathrm{g} / \mathrm{mL}$ respectively. The percentage assay of levetiracetam was $99.87 \%$. The method was validated by determining its accuracy, precision and system suitability. The results of the study showed that the proposed RP-HPLC method is simple, rapid, precise and accurate, which is useful for the routine determination of levetiracetam in bulk drug and in its pharmaceutical dosage form.
\end{abstract}

Keywords: Levetiracetam, RP-HPLC, Estimation, and Tablets.

\section{Introduction}

Levetiracetam $^{1}$ is a novel antiepileptic agent; with a chemical name (S)-(2)-(2oxopyrrolidin-yl)butamide with a molecular formula $\mathrm{C}_{8} \mathrm{H}_{14} \mathrm{~N}_{2} \mathrm{O}_{2}$ and a molecular weight of 170.20. It is used as an adjunctive therapy in the treatment of partial seizures ${ }^{2}$. Literature 
survey reveals many chromatographic methods ${ }^{3-8}$ for the determination of levetiracetam, in biological fluids. So far, no assay procedure has been reported for the estimation of levetiracetam from pharmaceutical dosage form. The availability of an HPLC method with high sensitivity and selectivity will be very useful for the determination of levetiracetam in pharmaceutical formulations. The aim of the study was to develop a simple, precise and accurate reversed-phase HPLC method for the estimation of levetiracetam in bulk drug samples and in pharmaceutical dosage form.

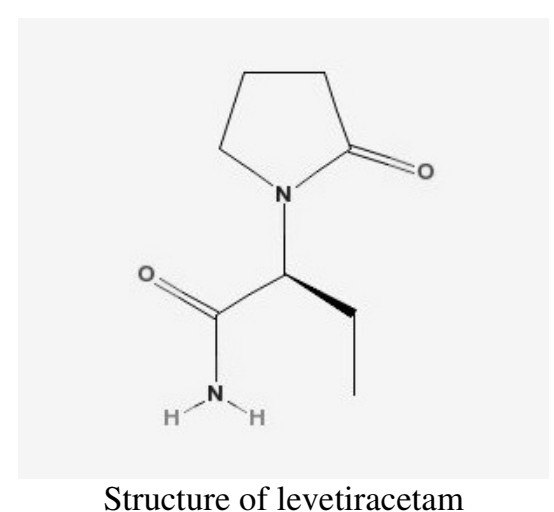

\section{Experimental}

\section{Materials and Methods}

Levetiracetam was obtained as a gift sample from Aurobindo Pharma Ltd, Hyderabad. Potassium dihydrogen orthophosphate was of analytical grade, supplied by M/s S.D.Fine Chem Limited, Mumbai. Acetonitrile and water used were of HPLC grade (Qualigens). Commercially available levetiracetam tablets (Levroxa 250mg, Ranbaxy) were procured from local market.

\section{Instrumentation}

Quantitative HPLC was performed on liquid Chromatograph, Water separation 2996, PDA detector module equipped with automatic injector with injection volume $20 \mu \mathrm{L}$, and 2693 pump. A RP C-18 Sun Fire column $(250 \times 4.6 \mathrm{~mm}$ i.d; particle size $5 \mu \mathrm{m})$ was used. The HPLC system was equipped with Empower Software.

\section{HPLC conditions}

The contents of the mobile phase were acetonitrile and $0.03 \mathrm{M}$ potassium dihydrogen phosphate ( $\mathrm{pH}$ adjusted to 3.0 with orthophosphoric acid) in the ratio of 15:85 v/v. They were filtered before use through a $0.45 \mu \mathrm{m}$ membrane filter, and pumped from the respective solvent reservoirs to the column at a flow rate of $1.0 \mathrm{~mL} / \mathrm{min}$. The run time was set at 10.0 min and the column temperature was ambient. Prior to the injection of the drug solution, the column was equilibrated for at least 30 min with the mobile phase flowing through the system. The eluents were monitored at $210 \mathrm{~nm}$.

\section{Preparation of standard stock solution}

A standard stock solution of the drug was prepared by dissolving $50 \mathrm{mg}$ of levetiracetam in $50 \mathrm{~mL}$ volumetric flask containing $30 \mathrm{~mL}$ of mobile phase, sonicated for about $15 \mathrm{~min}$ and then made up to $50 \mathrm{~mL}$ with diluent to get $1 \mathrm{mg} / \mathrm{mL}$ standard stock solution. 


\section{Working standard solution}

$10 \mathrm{~mL}$ of stock solution was taken in $50 \mathrm{~mL}$ volumetric flask and thereafter made up to $50 \mathrm{~mL}$ with mobile phase to get a concentration of $200 \mu \mathrm{g} / \mathrm{mL}$.

\section{Preparation of sample solution}

Twenty tablets (Levroxa 250mg, Ranbaxy) were weighed, and then powdered. A sample of the powdered tablets, equivalent to $50 \mathrm{mg}$ of the active ingredient, was mixed with $25 \mathrm{~mL}$ of diluent. The mixture was allowed to stand for $1 \mathrm{~h}$ with intermittent sonication to ensure complete solubility of the drug, and then filtered through a $0.45 \mu \mathrm{m}$ membrane filter, followed by adding mobile phase to obtain a stock solution of $1.0 \mathrm{mg} / \mathrm{mL}$. $2 \mathrm{~mL}$ of this solution was transfered to a $10 \mathrm{~mL}$ volumetric flask and made up to sufficient volume with mobile phase to give a concentration of $200 \mu \mathrm{g} / \mathrm{mL}$.

\section{Linearity}

Aliquots of standard levetiracetam stock solution were taken in different $10 \mathrm{~mL}$ volumetric flasks and diluted up to the mark with the mobile phase such that the final concentrations of levetiracetam are in the range of $20-240 \mu \mathrm{g} / \mathrm{mL}$. Each of these drug solutions $(20 \mu \mathrm{L})$ was injected three times into the column, and the peak areas and retention times were recorded. Evaluation was performed with PDA detector at $210 \mathrm{~nm}$ and a calibration graph was obtained by plotting peak area versus concentration of levetiracetam (Figure 2).

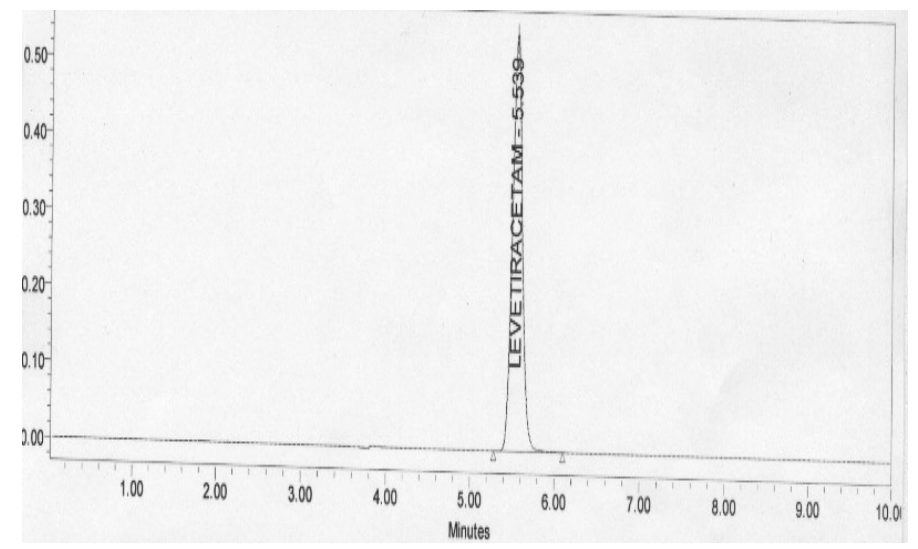

Figure 1. Typical chromatogram of levetiracetam by HPLC

The plot of peak area of each sample against respective concentration of levetiracetam was found to be linear in the range of $20-240 \mu \mathrm{g} / \mathrm{mL}$ with correlation coefficient of 0.999 . Linear regression least square fit data obtained from the measurements are given in Table 1 . The respective linear regression equation being $\mathrm{Y}=22119.684 \mathrm{x}+6829.3428$. The regression characteristics, such as slope, intercept, and \% RSD were calculated for this method and given in Table 1.

Table 1. Linear regression data for calibration curves.

\begin{tabular}{lc}
\hline Drug & Levetiracetam \\
\hline Concentration range, $\mu \mathrm{g} / \mathrm{mL}$ & $20-240$ \\
Slope, $\mathrm{m}$ & 22119.684 \\
Intercept, b & 6829.3428 \\
Correlation coefficient & 0.9999 \\
$\%$ RSD & 0.50 \\
\hline
\end{tabular}


Assay

$20 \mu \mathrm{L}$ of sample solution was injected into the injector of liquid chromatograph. The retention time was found to be 5.53 minutes. The amount of drug present per tablet was calculated by comparing the peak area of the sample solution with that of the standard solution. The data are presented in Table 2.

Table 2. Results of HPLC assay and recovery studies

\begin{tabular}{cccc}
\hline Sample & $\begin{array}{c}\text { Amount claim, } \\
\text { mg/tablet }\end{array}$ & $\begin{array}{c}\text { \% found by the proposed } \\
\text { method }\end{array}$ & \% Recovery* \\
\hline 1. & 250 & 99.85 & 101.37 \\
2. & 250 & 100.52 & 99.92 \\
3. & 250 & 99.26 & 99.37 \\
\hline
\end{tabular}

*Average of three different concentration levels.

\section{Recovery studies}

Accuracy was determined by recovery studies of levetiracetam, known amount of standard was added to the preanalysed sample and subjected to the proposed HPLC analysis. Results of recovery study are shown in Table 2 . The study was done at three different concentration levels.

\section{Results and Discussion}

The system suitability tests were carried out on freshly prepared standard stock solution of levetiracetam. Parameters that were studied to evaluate the suitability of the system are given in Table 3 .

Table 3. Validation summary

\begin{tabular}{cc}
\hline Validation Parameter & Results \\
\hline System Suitability: & 10718.73 \\
Theoretical plates, $\mathrm{N}$ & 1.14 \\
Tailing factor & 5.53 \\
Retention time in minutes & 0.16 \\
LOD, $\mu \mathrm{g} / \mathrm{mL}$ & 0.5 \\
LOQ, $\mu \mathrm{g} / \mathrm{mL}$ &
\end{tabular}

\section{Limit of detection (LOD) and limit of quantification $(L O Q)$}

The limit of detection (LOD) and limit of quantification (LOQ) for levetiracetam were found to be $0.16 \mu \mathrm{g} / \mathrm{mL}$ and $0.5 \mu \mathrm{g} / \mathrm{mL}$ respectively. The signal to noise ratio is 3 for LOD and 10 for LOQ.

From the typical chromatogram of levetiracetam as shown in Fig 1, it was found that the retention time was $5.53 \mathrm{~min}$. A mixture of acetonitrile and $0.03 \mathrm{M}$ potassium dihydrogen phosphate ( $\mathrm{pH}$ adjusted to 3.0 with orthophosphoric acid) in the ratio of 15:85 v/v was found to be most suitable to obtain a peak well defined and free from tailing. In the present developed HPLC method, the standard and sample preparation required less time and no tedious extraction were involved. A good linear relationship ( $r=0.9999)$ was observed between the concentration range of $20-240 \mu \mathrm{g} / \mathrm{mL}$. Low values of standard deviation are indicative of the high precision of the method. The assay of levetiracetam tablets was found to be $99.87 \%$. From the recovery studies it was found that about $100.24 \%$ of levetiracetam was recovered which indicates high accuracy of the method. 
The absence of additional peaks in the chromatogram indicates non-interference of the common excipients used in the tablets. This demonstrates that the developed HPLC method is simple, linear, accurate, sensitive and reproducible. Thus, the developed method can be easily used for the routine quality control of bulk and tablet dosage form of levetiracetam within a short analysis time.

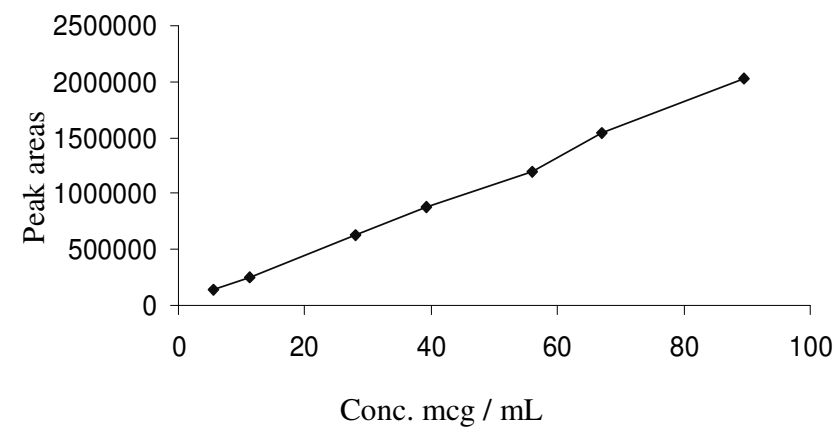

Figure 2. Calibration curve of levetiracetam by HPLC

\section{Acknowledgements}

The authors are grateful to M/s Aurobindo Pharma, Hyderabad for the supply of as a gift sample levetiracetam and to the Management, Sultan-Ul-Uloom College of Pharmacy, Hyderabad, for providing the necessary facilities to carry out the research work.

\section{References}

1. Martindale-The Complete drug reference, 2005, 34, 366.

2. Lancelin F, Franchon E, Kraoul L, Garciau I, Brovedani S, Tabaouti K, Landré E, Chassoux F, Paubel P and Piketty M L, Ther Drug Monit., 2007, 29, 576.

3. Guo T, Oswald L M, Mendu D R and Soldin S J, Clin Chim Acta. 2007, 375, 115.

4. Jain D S, Subbaiah G, Sanyal M, Pal U and Shrivastav P S, Rapid Commun Mass Spectrom. 2006, 20, 2539.

5. Martens-Lobenhoffer J and Bode-Böger S M, J Chromatogr B: Analyt Technol Biomed Life Sci., 2005, 819, 197.

6. Pucci V, Bugamelli F, Mandrioli R, Ferranti A, Kenndler E and Raggi M A, Biomed Chromatogr., 2004, 18, 37.

7. Shihabi Z K, Oles K and Hinsdale M, J Chromatogr. A. 2003, 1004, 9.

8. Ratnaraj N, Doheny H C and Patsalos P N, Ther Drug Monit., 1996, 18, 154. 


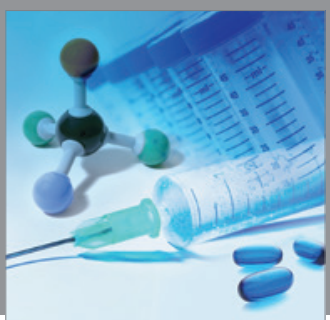

International Journal of

Medicinal Chemistry

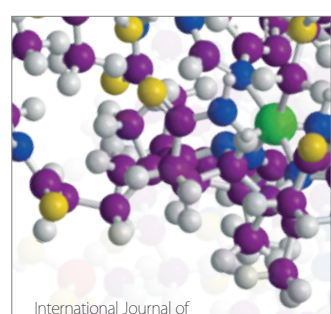

Carbohydrate Chemistry

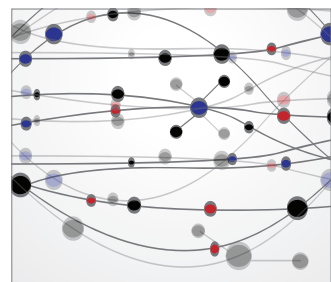

The Scientific World Journal
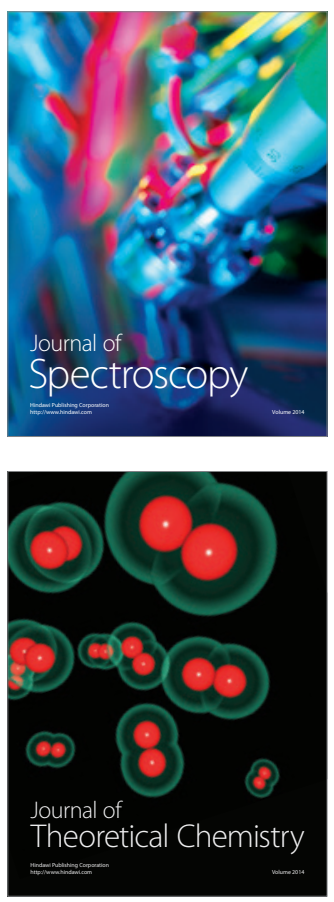
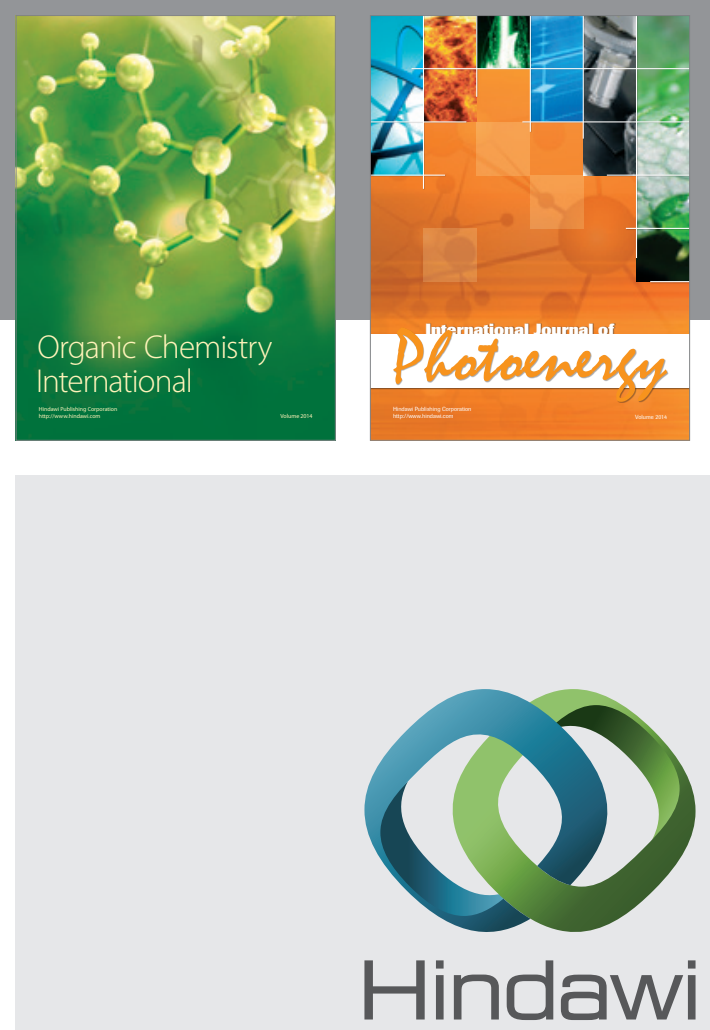

Submit your manuscripts at

http://www.hindawi.com
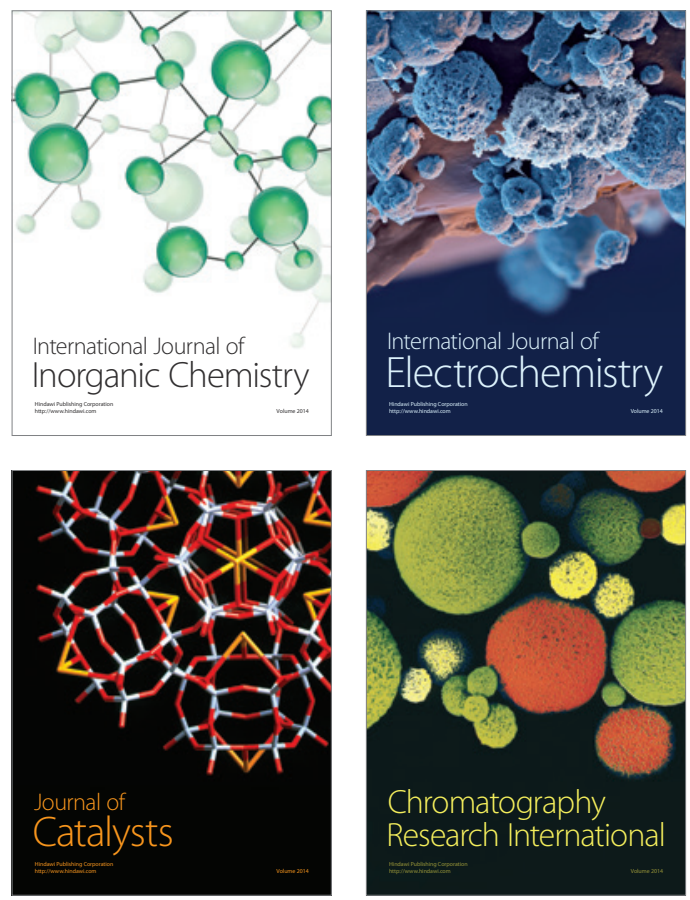
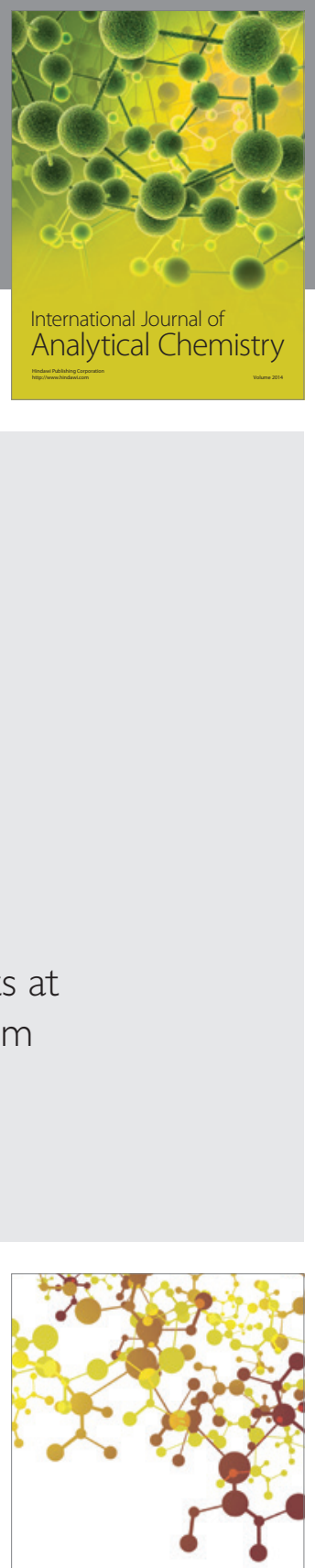

Journal of

Applied Chemistry
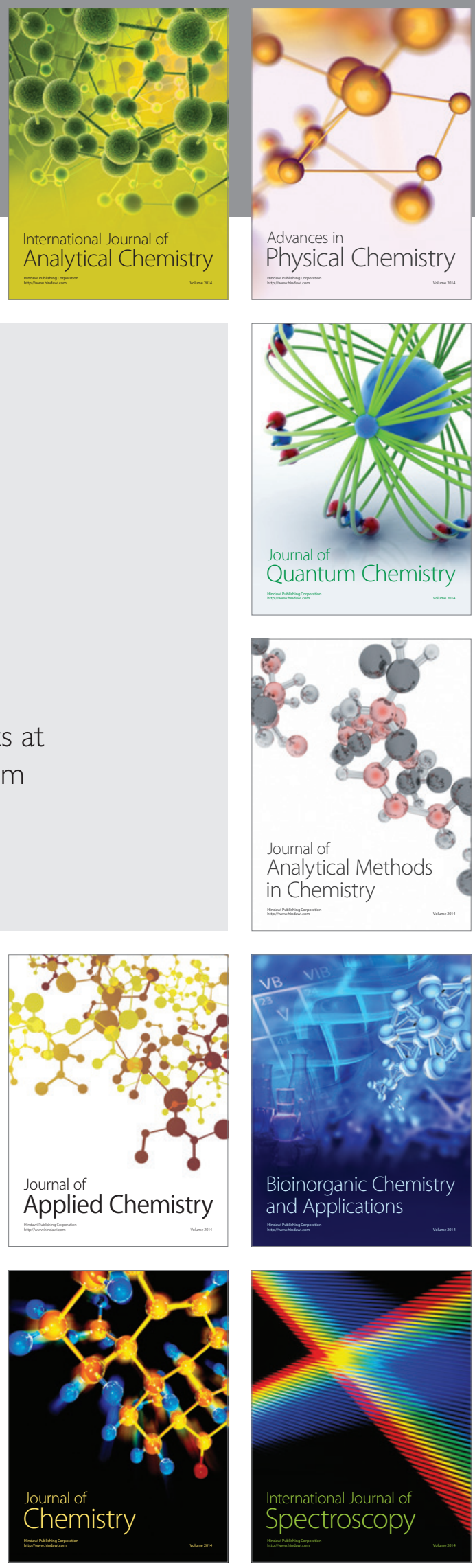